\title{
Construcción de una propuesta didáctica para favorecer el desarrollo del lenguaje en su función cognitiva ${ }^{1}$

\author{
Claudia Marcela Rincón W² \\ cmrincon@pedagogica.edu.co
} \\ Martha Leonor Sierra Ávila ${ }^{4}$ \\ mlsierra@pedagogica.edu.co \\ María Ivoneth Lozano Rodríguez ${ }^{3}$ \\ livoneth@yahoo.com \\ Zulma Patricia Zuluaga 0 campo $^{5}$ \\ zzuluaga@pedagogica.edu.co \\ Grupo de Comunicación y Lenguaje de la Universidad Pedagógica Nacional Facultad de Educación, Proyecto Curricular de Educación Infantil
}

\section{RESUMEN}

El presente artículo tiene como propósito mostrar una panorámica del estado de la investigación "Construcción de una propuesta didáctica para favorecer el desarrollo del lenguaje en su función cognitiva" realizada en niños de 3 meses a 5 años, para lo cual se ubican los antecedentes investigativos, el horizonte teórico y las fases de desarrollo metodológico desde la perspectiva de la investigación-acción, destacando las estrategias utilizadas en la interacción con las educadoras participantes, con quienes se hace la construcción conjunta de la propuesta didáctica.

\section{Palabras Clave}

Lenguaje, lengua, aprendizaje, didáctica, interacción, reflexión.

\section{ABstRact}

This article gives an overview of the current state of the research project "Construction of a Teaching Proposal to Aid the Development of Language in its Cognitive Function" in children from 3 months to 5 years of age. It reviews the previous research, explains the theoretical perspectives and describes the phases of methodological development. The authors specify their strategies for interaction in which the researchers work with the teachers. This project uses the methodological perspective of participatory action research, which means that the teaching proposal is created together with these educators.

\section{KEYWORDS}

Language faculty, language, learning, teaching, interaction, reflection.

1 En el desarrollo del proyecto también participó la investigadora Consuelo López Rodríguez, quien en ese momento hacía parte del Grupo de investigación y a quien agradecemos sus valiosas contribuciones.

2 Docente de planta y coordinadora de investigación del grupo de Comunicación y Lenguaje de la Universidad Pedagógica Nacional, Facultad de Educación, Proyecto Curricular de Educación Infantil. Magíster en Estructuras y Procesos de Aprendizaje.

3 Docente catedrática e investigadora de la Universidad Pedagógica Nacional, Proyecto Curricular de Educación Infantil. Docente catedrática e investigadora del grupo de investigación del Lenguaje Identidad y Cultura de la Universidad Distrital Francisco José de Caldas. Docente de planta de la Normal Distrital María Montessori. Magíster en Estructuras y Procesos de Aprendizaje.

4 Docente ocasional tiempo completo e investigadora del grupo de Comunicación y Lenguaje de la Universidad Pedagógica Nacional, Proyecto Curricular de Educación Infantil. Docente catedrática de la Fundación Universitaria Los Libertadores. Magíster en Orientación.

5 Docente catedrática e investigadora del grupo de Comunicación y Lenguaje de la Universidad Pedagógica Nacional, Proyecto Curricular de Educación Infantil. Docente de la Pontificia Universidad Javeriana. Magíster en Lingüística. 


\section{Introducción}

$\mathrm{L}$

a "Construcción de una propùesta didáctica para favorecer el desarrollo del lenguaje en su función cognitiva" es una investigación que surge de los resultados obtenidos en la investigación "Formas de ayuda que emplea el educador infantil para favorecer el desarrollo del lenguaje en su función cognitiva", desarrollada por el grupo de investigación de Comunicación y Lenguaje del Proyecto Curricular de la Licenciatura en Educación Infantil de la Universidad Pedagógica Nacional durante los años 2002 y 2003.

En este sentido, la investigación de formas de ayuda se constituye en un antecedente importante al demostrar que las actividades pedagógicas y las acciones discursivas empleadas por las educadoras infantiles que participaron en la investigación no se constituyen en formas de ayuda para el desarrollo del lenguaje y la cognición, en la medida en que no propician procesos de interacción que favorezcan la internalización del lenguaje en relación con los usos y los contextos de realización de los diferentes sistemas de signos que culturalmente se construyen a partir de éste. Así mismo, se pudo determinar que no se promueve el conflicto sociocognitivo, la negociación de significados y el aprendizaje autónomo.

Las conclusiones anteriores en torno a la práctica de los educadores nos llevaron a reconocer que en la construcción de formas de ayuda es indispensable generar espacios en los que el maestro reflexione sobre su propia práctica, de manera que objetive la forma como favorece el desarrollo del lenguaje y orienta los procesos de enseñanza y aprendizaje de la lengua materna; proceso que implica la reflexión simultánea acerca de los referentes teóricos desde los que se abordan tales conceptos. Dentro de este marco el interrogante que se planteó fue: ¿Qué implicaciones tiene estructurar una propuesta didáctica con educadoras infantiles que posibilite la construcción de formas de ayuda para favorecer el desarrollo del lenguaje en su función cognitiva en niños de 3 meses a 5 años?

Así, el propósito fundamental de esta investigación fue construir una propuesta didáctica con las educadoras con quienes se efectuó la investigación anterior. Para el logro de este propósito, se hizo necesario promover espacios de reflexión sobre la historia personal y profesional de las educadoras infantiles, suscitar la construcción y la reelaboración teórica en relación con el lenguaje, el aprendizaje y la enseñanza, y desarrollar procesos de apoyo que posibiliten la resignificación de sus propuestas didácticas.

La investigación se desarrolló en las dos primeras fases con 15 educadoras de dos de los jardines infantiles donde realizan sus prácticas las estudiantes del Proyecto Curricular de Educación Infantil de la UPN y en la fase final de acompañamiento con dos de ellas: una responsable del grupo de bebés y otra encargada de los niños entre los 3 y 5 años, quienes aceptaron vincularse activamente a la investigación sin prevenciones por el hecho de ser observadas y a ceder de su tiempo para los procesos de autorreflexión y reflexión colectiva, condiciones fundamentales para un proceso de investigación-acción.

\section{La construcción de formas de ayuda es indispensable generar espacios en los que el maestro reflexione sobre su propia práctica.}

La investigación se apoyó en el paradigma sociocrítico de la investigación cualitativa. En este sentido, el referente principal es la propia praxis, desde la cual se propende por generar la autorreflexión de quienes participan en los procesos investigativos. La perspectiva metodológica fue la investigación-acción, la cual permite no solamente analizar e interpretar una realidad específica, sino contribuir con un proceso de investigación en la transformación de las prácticas y las concepciones de las educadoras a través de la construcción de una propuesta didáctica.

\section{Fundamentos teóricos}

El proyecto de investigación tiene como ejes teóricos fundamentos lingüísticos-discursivos, psicológicos-pedagógicos y didácticos. 


\section{Fundamentos lingüísticos-discursivos}

En este proyecto se asume el desarrollo del lenguaje y el aprendizaje de la leñgua desde la perspectiva interaccionista desarrollada por Vigotsky (1999 y 2000) y Bruner (1990, 1995, 2000 y 2001) en la medida en que el lenguaje es concebido como una herramienta simbólica, como un proceso psicológico superior que tiene su origen en el plano de lo interpsicológico para posteriormente pasar al plano de lo intrapsicológico.

Así mismo, desde los aportes de Baena (1996), se entiende que el lenguaje permite al hombre, además de la comunicación, la transformación y recreación de la realidad natural y social a partir de la interacción constante con los otros. Desde esta perspectiva, se reconoce en el lenguaje una función cognitiva, en la medida en que posibilita al hombre la representación de la realidad a través de signos, que pueden ser "imágenes, palabras o cualquier otro símbolo [que] en cierto sentido, son algo así como un «medium» entre el hombre y la realidad" (Bruner, 2001: 122). De igual forma, se pone de relieve la función interactiva del lenguaje, al reconocer que la actividad mental surge como resultado de la interacción del hombre con los "otros". De acuerdo con Halliday la construcción de las ideas se da en un proceso de "intercambio de significados en contextos interpersonales [... en los cuales] mediante actos cotidianos de significación, la gente representa la estructura social, afirmando sus propias posiciones y sus propios papeles, lo mismo que estableciendo y transmitiendo los sistemas comunes de valor y conocimiento" (1994: 10).

Por último, la transformación de la realidad a partir del lenguaje evidencia su función recreativa o estética, la cual brinda la posibilidad de reconfigurar la realidad en forma de mundos posibles, en donde cobra especial importancia la expresión de la subjetividad.

Estas funciones del lenguaje se materializan a través de diferentes sistemas de signos construidos socialmente. En particular, se considera la lengua, con base en los desarrollos teóricos de van Dijk (1983), como un sistema de signos configurado a partir de tres dimensio- nes: morfosintáctica, semántica y pragmática, las cuales actúan de manera complementaria.

\section{Fundamentos psicológicos-pedagógicos}

El aprendizaje es entendido como un proceso de construcción social, en el que el niño es considerado como constructor de su aprendizaje a medida que interactúa con el medio natural y social, en situaciones significativas y auténticas. De esta manera, "cualquier función presente en el desarrollo cultural del niño, aparece dos veces o en dos planos distintos. En principio aparece entre las personas y como una categoría interpsicológica, para luego aparecer en el niño como una categoría intrapsicológica" (Vigotsky, citado en Wertsch, 1988: 77).

Dado el carácter social ya enunciado, se deduce entonces que el proceso de enseñanza y de aprendizaje es en esencia interactivo. En este sentido, se reconoce el concepto de Zona de Desarrollo Próximo planteado por Vigotsky como "la distancia entre el nivel real de desarrollo, determinado por la capacidad de resolver independientemente un problema, y el nivel de desarrollo potencial, determinado a través de la resolución de un problema bajo la guía de un adulto o en colaboración con otro compañero más capaz" (Vigotsky, 1988: 133). En otras palabras, es la diferencia entre el nivel de las tareas resueltas por el niño con la ayuda del adulto o un par más capaz y el nivel de tareas realizadas de manera independiente.

Para que dicha interacción favorezca el aprendizaje, por una parte, se estructura de manera colaborativa y bidireccional, orientada hacia la internalización de los conocimientos que en algún momento el adulto ayudó a construir $\mathrm{y}$, de otra, tales conocimientos deberán generar constantemente nuevos conflictos sociocognitivos o problemas exigentes y desafiantes que dinamicen el proceso de construcción de los mismos.

\section{Fundamentos didácticos}

La didáctica es entendida como un campo de acción, reflexión y recontextualización de saberes pedagógicos y disciplinares, cuyo objeto de estudio es el proceso de enseñanza en estrecha relación con el proceso de aprendizaje, por 
tanto no puede ser considerada como algo neutro que se ajusta a cualquier dinámica de interacción en el aula, sino que su concreción depende de la concepción que se tengà de dicho proceso, de la intencionalidad que lo orienta, del contexto en que se da y del campo disciplinar al que va dirigido.

Así, cuando la preocupación se centra fundamentalmente en el cómo hacer, se privilegia la dimensión técnica y la práctica pedagógica se disocia de las preguntas sobre el por qué y para qué hacer. Por el contrario, si la preocupàción está en la necesidad de comprender la pertinencia cultural de los procesos de enseñanza y aprendizaje, para desde allí proponer y asumir tareas históricamente transformadoras, su interés es de orden investigativo y su finalidad es trascendental; la mirada está dirigida hacia el por qué y el para qué, concediéndole una especial importancia "al saber" como una construcción social que se da intencionalmente en un contexto cultural particular. La pregunta por el cómo y el qué, entonces, se resignifican en una constante reflexión sobre la práctica.

La didáctica desde este marco es entendida como un campo de investigación que, específicamente, asume modalidades propias de la investigación-acción, en tanto que el maestro como investigador es a la vez actor y observador del campo que investiga y orienta sus acciones hacia la transformación de sus prácticas (Jolibert, 1999).

Así, la didáctica vista desde la perspectiva investigativa permite la reflexión mas allá de las preocupaciones clásicas por los métodos, los contenidos y la relación entre éstos, como elementos centrales de la didáctica. Reconoce entonces la importancia de otros aspectos que también se constituyen en problemas al interior de la didáctica,

[...] los modos como el docente aborda los temas de su campo y que se expresan en el tratamiento de los contenidos, los supuestos que maneja respecto del aprendizaje, la utilización de prácticas metacognitivas, el estilo de negociación de significados que genera, las relaciones entre la práctica y la teoría [...] y la particular relación entre el saber y el ignorar (Litwin, 2000: 97).
Todos estos aspectos constituyen lo que la autora denomina configuración didáctica, entendida como la manera particular como el docente favorece los procesos de construcción de conocimiento. $\mathrm{Y}$ en este sentido, dan cuenta de ella los tipos de preguntas, los procesos interactivos, cognitivos y metacognitivos que se proponen y las rupturas con los saberes cotidianos, entre otros, los cuales, como lo afirma Litwin (98) permiten reconocer

[...] una clara intención de enseñar, de favorecer la comprensión de los alumnos y de generar procesos de construcción de conocimiento, con lo cual se distinguen claramente de aquellas configuraciones no didácticas, que implican sólo la exposición de ideas o temas, sin tomar en cuenta los procesos de aprender del alumno.

De acuerdo con Rincón (2003), la unidad apropiada para el análisis de la configuración didáctica es la secuencia didáctica, la cual está determinada por la concepción de aprendizaje y de enseñanza que la orienta, unas estrategias y un rol particular que asumen tanto el maestro como el estudiante.

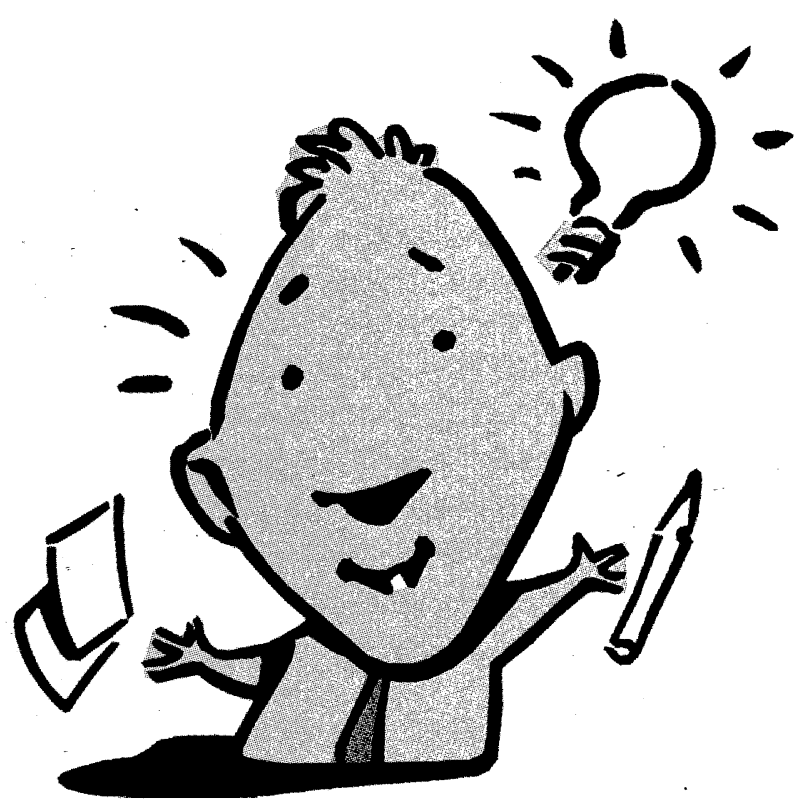




\section{Desarrollo de la propuesta didáctica}

Desde la perspectiva disciplinar, pedagógica, didáctica e investigativa planteada anteriormente, la propuesta didáctica se desarrolló a través de tres fases: sensibilización, fundamentación y acompañamiento, las cuales no se trabajaron de manera lineal, sino en constante interrelación.

\section{Fase de sensibilización}

La fase de sensibilización tuvo como propósito favorecer espacios de reflexión sobre la historia personal y profesional de las educadoras infantiles, al posibilitar la confrontación de sus concepciones y prácticas en torno al lenguaje, el aprendizaje y la enseñanza. Esto les.permitió reconocerse como sujetos históricos, resultado de un conjunto de interacciones que de una $u$ otra manera determinan su rol como educadoras, así como también la forma como han asumido el lenguaje en su proceso de enseñanza.

Lo anterior fue facilitado mediante estrategias como el juego, el dibujo, la expresión corporal, el relato, la escritura y una entrevista complementaria. La metodología empleada permitió a las educadoras reconocerse, exteriorizar su realidad, para luego compartirla y finalmente reflexionarla.

El análisis de las historias de vida reveló una influencia importante de tipo familiar asociada con experiencias gratas, relacionadas con el disfrute de la lectura de cuentos por parte de los padres, con las oportunidades de expresión libre y espontánea en situaciones familiares y con el rol de cuidadora de hermanos.

De igual manera reveló el impacto de las experiencias escolares asociado, en la mayoría de los casos, con situaciones no gratas por su carácter represivo, qúe inhibían y generaban sentimientos de inseguridad y, en una minoría, con experiencias que posibilitaron la participación y el desarrollo de la expresión.

En relación con la formación académica de las educadoras se puede destacar que en la mayoría el interés por la pedagogía surgió accidentalmente a partir de una oportunidad laboral en el ámbito educativo. En otros casos, no se presenta formación profesional y algunas sólo tienen los primeros grados de básica secundaria.

Con respecto a las concepciones se encontró que las educadoras, cuando definen el lenguaje, lo hacen desde el reconocimiento de sus funciones, y que principalmente privilegian su función comunicativa y expresiva, haciendo alusión a la manifestación de sentimientos y a la expresión de ideas: "El lenguaje es poder expresarnos y comunicarnos con las demás personas".

Otras educadoras lo definen a partir del reconocimiento de diferentes sistemas dẽ significación verbal o no verbal, dentro de ló que mencionan con mayor frecuencia el gesto, la escritura y el lenguaje oral, y con menor frecuencia la sonrisa, el contacto físico, las señas, la caricia y el movimiento: "El lenguaje es una manera de expresarnos tanto verbal, escrita, gestual; donde podemos expresar lo que sentimos y al mismo tiempo saber lo que quiere decir mi cuerpo".

Esta concepción del lenguaje se reitera cuando las educadoras caracterizan el lenguaje de sus niños o mencionan las estrategias que utilizan para enseñarlo: "Los niños de 2 a 3 años tienen un buen lenguaje, porque se expresan a través de su cuerpo, con sus manos, ojos; lógico que a su edad están bien”.

Cuando las educadoras hacen alusión a las estrategias utilizadas se deja ver en forma implícita una concepción centrada especialmente en la lengua como sumatoria de elementos: "Les enseño a que reconozcan primero las vocales, que sepan cómo funcionan y [que] donde las vean puedan diferenciarlas, pronunciando claro para que vayan afianzando más los sonidos”.

Como se puede apreciar, se da especial importancia a la enseñanza de la letra, el sonido y la palabra como elementos constitutivos de la lengua, que deben ser aprendidos a través de procesos de composición y descomposición. Las educadoras relacionan la adquisición del lenguaje con el aprendizaje de la lectura y la escritura, contemplando sólo aspectos referentes a la forma: buena letra, ortografía, el manejo de los signos de puntuación y la lectura en voz alta.

En cuanto a la concepción de enseñanza que tienen las educadoras se aprecia una marcada tendencia a reconocerla desde una perspec- 
tiva tradicional, centrada en el educador como eje central del proceso, en la medida en que es él quien porta el saber, el cual es transmitido de manera mecánica: "Enseñar es impartir un saber, es instruir, y el maestro es quien organiza y transmite el saber".

Esta forma de entender el proceso de enseñanza se ratifica al mencionar las estrategias utilizadas, especialmente en la enseñanza de la lengua, en la que se da prioridad a procesos perceptivos motrices y a la repetición como herramienta para el aprendizaje. Se validan prácticas basadas en la imitación, el refuerzo, la estimulación, la memorización y la manipulación de los objetos, y que en este sentido, están sustentadas en concepciones tradicionales, en las que el niño asume un papel pasivo de receptor: "Yo les digo una rima y después empezamos a repetir y a repetir, luego les pregunto ¿¿de qué estamos hablando ahí? Y así hagas que el niño repita y repita, no sabe de qué habla, ni para qué habla, ni por qué habla, entonces paramos y hacemos preguntas."

Una minoría de las educadoras avanza hacia una concepción más constructiva del aprendizaje y de la enseñanza; de esta manera, tiene en cuenta los intereses y saberes previos de los niños como punto de partida para éstos, reconoce el juego, la lúdica, los ambientes novedosos y la actividad libre como condiciones para el aprendizaje, y de igual forma rescata el papel del educador como guía y orientador del proceso: "Utilizo estrategias de una manera libre, como cuando ellos quieren jugar con los títeres y hacen sus cuentos, ya que de esa forma el niño habla y dice lo que sabe y uno se da cuenta ahí de sus falencias".

Los procesos desarrollados con las educadoras permitieron reconocer-que en la medida en que se sienten escuchadas y valoradas se genera un clima de confianza que facilita la exposición libre de ideas, la autocrítica y el reconocimiento del error como punto de partida para la transformación pedagógica.

\section{Fase de fundamentación teórica}

Esta fase tuvo como propósito generar conjuntamente (educadoras e investigadoras) procesos de construcción y reconstrucción teórica en relación con las categorías de lenguaje, aprendizaje y enseñanza, retomando las concepciones de las educadoras así como sus prácticas pedagógicas para, desde allí, posibilitar la reconceptualización de dichas categorías. El referente principal en este proceso es la propia praxis, a partir de la cual la teoría se construye desde "una reflexión en la acción, desde la praxis como encuentro crítico [para] orientar la acción" (Pérez Serrano, 1994: 18-34).

\section{A partir de la reflexión sobre la experiencia pedagógica de las educadoras y de sus preguntas se construyeron procesos dinámicos que interrogaron tanto la teoría como la práctica desde una perspectiva dialéctica.}

El análisis de las categorías teóricas (lenguaje, aprendizaje y enseñanza) se realizó a través de los talleres "Las funciones y usos del lenguaje", "La lengua y su estructura" y "Relación entre lenguaje y pensamiento". Éstos se constituyeron en una estrategia macro que posibilita construir los elementos teóricos de forma colectiva entre educadoras e investigadoras. En este sentido, el taller se asumió como "una forma de enseñar y sobre todo de aprender, mediante la realización de «algo», que se lleva a cabo conjuntamente. Es un aprender haciendo en grupo" (Ander-Egg, 1991: 10). Así, a partir de la reflexión sobre la experiencia pedagógica de las educadoras y de sus preguntas se construyeron procesos dinámicos que interrogaron tanto la teoría como la práctica desde una perspectiva dialéctica.

En relación con los contenidos teóricos, cabe aclarar que debido a que las fases no tuvieron un carácter lineal sino interrelacional éstos fueron desarrollados de forma articulada con las reflexiones generadas en los talleres correspondientes a la fase de sensibilización, así como a los procesos contemplados en la fase de acompañamiento y de 
fundamentación como tal. De igual forma, se trabajó fundamentalmente la categoría de lenguaje, ya que las otras categorías (aprendizaje y enseñanza) se llevaron a cabo en relación con ésta.

\section{Análisis de la fase}

El análisis estuvo centrado en reconocer cómo se dan los procesos de transferibilidad, entendidos como la capacidad de las educadoras de utilizar lo aprendido para reflexionar sobre otros eventos, afrontar situaciones nuevas y así realizar nuevos aprendizajes. Estos procesos se hacen explícitos en sus intervenciones cuando transfieren el concepto teórico trabajado en el taller a un contexto de una experiencia pedagógica pasada o cuando evocan sus experiencias de vida, como se aprecia en el siguiente registro:

Educadora: Profe pero vea que en esta parte los niños ya tieǹen como ese conocimiento acerca de lo pragmático sin que ellos sean conscientes de eso, a mí me pasó. Yo les coloque la frase "La mula lame la loma" y un niño me dijo: "Pero profe, ¿ cómo lame la loma?” ¿Cómo? Me tocó volver a recrear un cuento, pero me corchó, y ahora yo digo, ipero de verdad! el niño tiene toda la razón, porque, o sea, ¡esa frase es ilógica!

Las educadoras también realizaron ejemplificaciones que les ayudaron a comprender, desde otros contextos de significación, algunos conceptos en torno al lenguaje y la estructura de la lengua. El siguiente registro se constituye en evidencia de dicho proceso:

Investigadora: vamos a ver, a mirarlos de una manera más concreta. Decimos que la lengua es un sistema, ¿Qué significa eso de que la lengua es un sistema?

Educadora 4: sí, bueno, hay sistemas de toda clase, por ejemplo el sistema digestivo; o a nivel de sociales veíamos los sistemas sociales que hay, la familia es un sistema.

De igual forma, se observaron apropiaciones conceptuales por parte de las educadoras en relación con las concepciones teóricas en torno al aprendizaje, la enseñanza y el lenguaje, en tanto ubican sus prácticas dentro de modelos conductuales con predominancia de la función comunicativa y los aspectos formales de la lengua, a través de "sus voces" (tomadas de las concepciones que expresaron en las actividades iniciales de la fase de sensibilización), como se evidencia en el siguiente registro:

Investigadora: Busquemos otras voces donde ustedes dicen cómo aprendieron, $\mathrm{y}$ miren una voz en donde se vea esa prioridad frente a lo perceptivo y a lo motriz en lo que yo digo y en lo que hago.

Educadora 3: ¡Aquí!, en esta voz dice que aprendí por asociaciones de los grafemas de manera mecánica, letra y mano.

Investigadora: Muy bien, busquemos otra voz que nos deje ver esa parte de lo perceptivo y lo motriz.

Educadora 3 (lee): "Me enseñaron por repetición e imitación, planas y más planas”.

Las apropiaciones conceptuales logradas por las educadoras en esta fase fueron posteriormente reflexionadas, confrontadas y enriquecidas en las distintas estrategias adelantadas en la fase de acompañamiento.

\section{Fase de acompañamiento}

Se concibe el acompañamiento, desde la perspectiva de la investigación-acción, como una construcción conjunta de criterios pedagógicos y didácticos entre educadoras e investigadoras, para asumir in situ una tarea o acción educativa que implica procesos de planeación, ejecución y evaluación.

El acompañamiento se planteó a partir de tres estrategias: "Leyéndome a mí misma y leyendo a otras", "Construyendo juntas" y "Construyendo autónomamente". Esta última se encuentra actualmente en proceso de análisis.

\section{Leyéndome a mí misma y leyendo a otras}

El propósito de esta estrategia fue reflexionar sobre la propia práctica y la de los demás como una herramienta fundamental para favore- 
cer procesos de transformación pedagógica. En el momento de planeación se buscó que las educadoras prepararan desde sus saberes previos una actividad pedagógica para favorecer el desarrollo del lenguaje, la cual fue registrada y analizada.

El desarrollo de la actividad fue realizado por la educadora y la intervención de la investigadora se redujo fundamentalmente al registro de la actividad a través de medios audiovisuales y escritos.

El análisis conjunto se realizó inicialmente entre las investigadoras para establecer categorías de reflexión y posteriormente entre investigadoras y educadoras, con miras a generar una confrontación entre teoría y práctica a partir del análisis de la configuración didáctica que caracterizó la práctica pedagógica de las educadoras.

\section{Análisis de la estrategia}

Las educadoras se apoyaron, para la planeación, en un formato establecido por la institución, en el que se requiere formular diariamente un objetivo, un indicador de logro y una actividad atendiendo a las dimensiones planteadas por el MEN. De igual manera, el formato establece el desarrollo de lo que el ICBF denomina momentos pedagógicos: bienvenida, vamos a explorar, vamos a crear, vamos a jugar, vamos a comer y vamos a casa.

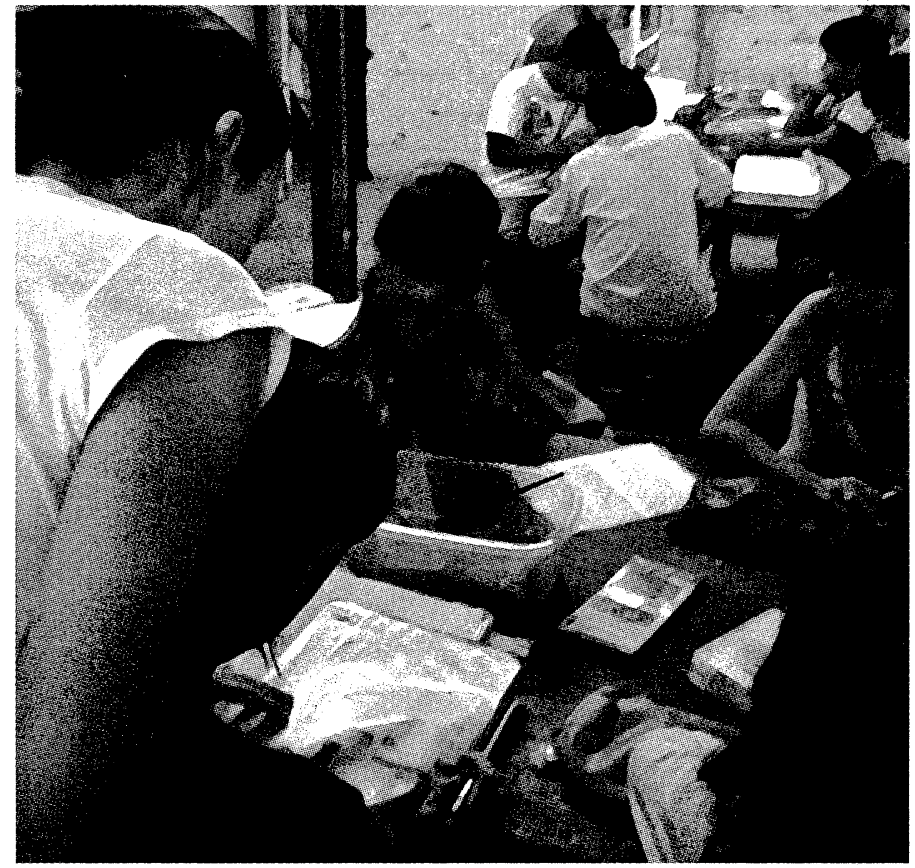

102
En la planeación de la educadora 1 (grupo de 3 meses a 3 años) se reconoce una secuencia didáctica en la que no se evidencia un hilo conductor que articule los diferentes momentos, sino que éstos se trabajan como actividades aisladas.

Para la "bienvenida" propone: "Recibimiento-oración-canto y juego con sonajeros". En "vamos a explorar" escribe: "A través de una canción realizo varios movimientos $\mathrm{y}$ nombro las partes del cuerpo". Y en "vamos a crear" dice: "Acomodo a los niños en un espacio amplio para luego ubicarme frente a ellos y con ayuda de la música realizaré los movimientos".

De esta manera, la configuración didáctica evidencia una secuencia progresiva no lineal, en la medida en que no se reconoce una progresión temática como eje estructurante y por lo tanto no hay "un desarrollo gradual y continuo de un tema o problema" (Litwin, 2000: 109), lo cual dificulta el establecimiento de relaciones lógicas $y$, por ende, el desarrollo de procesos cognitivos.

Por otra parte, la planeación no explicita objetivos en relación con las dimensiones elegidas para ser trabajadas en este día. Es así como selecciona las dimensiones motriz y socio afectiva, y dentro de ésta el lenguaje, y únicamente plantea "Mira con atención el rostro de un adulto que le habla" como un indicador de logro, sin especificar a cuál dimensión hace referencia o de qué manera puede ser un indicador que evidencie alcances en las diferentes dimensiones.

En la planeación de la educadora 2 (grupo de 3 a 5 años), tampoco se explicitan objetivos en relación con el lenguaje, lo cual es justificado por la importancia que da a la improvisación.

En relación con el desarrollo de la planeación, se pueden reconocer, en el caso de la educadora 1, los siguientes momentos:

El recibimiento de los bebés, la bienvenida en la que los acomoda en las colchonetas y les canta la canción "buenos días" (situación que aprovecha para que saluden al amiguito de la mano o con un beso), realiza una oración, desarrolla la actividad programada sobre len- 
guaje, toman el desayuno y cierra con el cambio de pañal.

Aunque esta organización a través de los momentos pedagógicos determina una secuencia didáctica, no se hace explícita una reflexión sobre el por qué ni el para qué de esas acciones, y al no hacerse conscientes, se corresponden con estrategias de carácter activista, donde las intervenciones de la maestra caen en lo mecánico y los niños desempeñan un rol pasivo.

La actividad específica para el desarrollo del lenguaje fue organizada de la siguiente manera: "Ubicación de los bebés en colchonetas frente a la educadora, quien entona la canción «Saco mis manitas» haciendo uso de gestos y movimientos para dar significación al texto y apoyada de un casete que reproduce la canción simultáneamente".

En esta actividad se reconoce que para la educadora el desarrollo del lenguaje implica no sólo el hablar, sino la intervención de otros sistemas, tales como la música y el gesto, en la construcción de la significación. A pesar de ello, en la interacción con la educadora se hace evidente que tales acciones corresponden a un saber intuitivo, ya que no son producto de un saber reflexivo en torno al lenguaje.

En relación con el desarrollo de la planeación de la educadora 2 , se pudieron reconocer en la jornada los momentos denominados antes, $d u$ rante y después:

En el antes la educadora introduce el tema a trávés de la enseñanza de una canción, en la que busca que los niños se saluden y realicen ejercicios de relajación con diferentes partes del cuerpo.

En el durante se desarrolla el tema a partir de la narración construida por la educadora con ayuda de los niños y apoyada con dibujos para que ellos enuncien las partes del cuerpo que se están dibujando.

Posteriormente se hace la reconstrucción de la historia a través de preguntas, con la intención de que los niños/as recuerden la secuencia narrativa y permitan que la maestra explicite una enseñanza sobre el valor de la amistad.
En el después se da la materialización del aprendizaje construido a través de la representación de la historia con arcilla.

La secuencia didáctica evidenciada en esta actividad permite reconocer que a pesar de que la organización didáctica manifiesta una secuencia progresiva lineal, en la que se da un desarrollo continuo de un tema o problema, en este caso el reconocimiento de las partes del cuerpo, los procesos de construcción de conocimiento están orientados fundamentalmente al desarrollo de procesos cognitivos y discursivos básicos, en la medida en que los requerimientos que se hacen a los niños promueven sólo la identificación y denominación sin exigir mayores procesos de reflexión, análisis, y/o establecimiento de relaciones, tal como se evidencia en el siguiente registro:

E: Pero yo también en el parque veo como arbolitos, ¿sin arbolitos en el parque? Adriana, en el parque estaba un niño, vamos a dibujar un niño, ¿qué le falta a ese niño?

$\mathrm{N}$ : Los ojos.

E: ¡Ay, los ojos!, ¿Qué mas le falta a ese niño?.

Nñ: La boca.

$\mathrm{E}:$ ¿Qué más le falta?, la nariz, yo pensé que ese niño no respiraba. ¿Qué más le falta?

Nñ: E1 cuello, una pierna.

Los procesos cognitivos y discursivos, esenciales en los procesos de aprendizaje, se podrían desarrollar al trabajar con los niños estrategias como la explicación y la argumentación, en tanto favorecen el desarrollo discursivo de forma simultánea con el pensamiento crítico y reflexivo al problematizar una realidad y buscar las aclaraciones y razones necesarias en la construcción de sentido que lleven a dinámicas de negociación y acuerdo.

De esta manera, si la educadora promoviera de forma intencional este tipo de acciones discursivas llevaría a los niños a reconocer las intencionalidades del "otro"; la importancia de los turnos para intercambiar puntos de vista, establecer secuencias y relaciones lógicas entre eventos, a aprender a ligar el discurso propio con el del "otro", a convencer, a compartir con otros y obviamente a llegar a acuerdos. 


\section{Construyendo juntas}

El objetivo fundamental de esta estrategia fue planear conjuntamente, investigadora y educadora, una secuencia didáctica para desarrollar el lenguaje en los niños, la cual se realizó posteriormente de manera autónoma por la educadora y finalmente fue objeto de reflexión con las investigadoras. El análisis conjunto favoreció la explicitación de las concepciones disciplinarias de la maestra en relación con el lenguaje y las concepciones pedagógicas que subyacen en la forma de enseñar de las educadoras, y a su vez permitió la confrontación con los elementos teóricos trabajados en la fase de fundamentación. Lo anterior condujo a la comprensión crítica sobre el para qué y el por qué de sus acciones.

\section{Análisis de la estrategia}

A pesar de que las educadoras mantuvieron en sus planeaciones los parámetros institucionales, en relación con la secuencia didáctica se pudo reconocer que en la planeación de la educadora 1 , a diferencia de su primera planeación, se identifica un hilo conductor en torno al tema de los animales, específicamente de la vaca, con una secuencia que guarda relación directa con el objetivo propuesto, "Estimular en los niños y las niñas el lenguaje a través del sonido de algunos animales", y el indicador de logro formulado, "Interioriza sonidos y movimientos de animales".

Al comparar la planeación con la desarrollada en la primera estrategia se nota que existe una intención en torno al lenguaje, a pesar de que no se explicite qué se logra en relación con éste.

En cuanto al desarrollo de las actividades realizadas, se puede reconocer, en la educadora 1 , una secuencia didáctica lineal acorde a lo planteado en su planeación con un hilo conductor que relaciona y da sentido a cada uno de los momentos:

En la "bienvenida" realiza una oración y hace énfasis en el saludo a través de una canción acompañada de acciones que conducen a los bebés a dar la mano como una forma cultural de reconocimiento del otro.
La actividad central comienza en el momento de "vamos a explorar" con la manipulación libre de varios animales de peluche que la educadora va ofreciendo a los niños indicándoles el nombre y el sonido que hace cada uno. Después elige la vaca, sacando de escena a los otros animales, y propone a los bebés darle un nombre: Susana.

Para "vamos a crear" entona la canción de la vaca Susana, la cual acompaña de movimientos y gestos que representan las acciones verbalizadas. En este momento se apoya en dos láminas con dibujos de la vaca para realizar descripciones de sus características y beneficios e igualmente hace una lectura de la palabra vaca que se encuentra escrita en cada cartel.

En el momento "vamos a comer" la educadora hace alusión constante a la leche como alimento proporcionado por la vaca. Para el momento de "vamos a jugar", la educadora emplea como estrategia provocadora el esconderse bajo una manta para ser buscada por los niños, acción que repite con la vaca y posteriormente con ellos.

En esta secuencia didáctica se aprecia una dinámica de mayor interacción y participación de los bebés, lo que refleja un avance en la concepción del niño como sujeto activo, que construye significados a partir de la experiencia en su relación con los adultos y los objetos. De esta forma, la educadora asume un papel de facilitador que favorece la construcción de la significación.

Aquí se puede inferir una intención orientada hacia la representación icónica, enactiva y simbólica de los animales por medio de sonidos y movimientos, como también la construcción de significación con la palabra y la imagen, tal como se evidencia en el siguiente registro:

E (mostrando la lámina con una vaca): Miren la vaquita, tiene pepitas negras y la boca con la que hace muuu. La vaca nos regala la leche con la que se preparan los teteros. $Y$ ¿dónde vive la vaca? En el campo. $Y$ ¿cómo camina la vaca? Así (apoyada en brazos y rodilla camina por el salón). Así, así, moviendo la colita (pide a los niños que la imiten). 
Otro elemento importante para analizar es el aprendizaje de y a través del lenguaje a partir del uso de estrategias pedagógicas. Es así como la educadora 1 , a diferencia de la actividad desarrollada en la primera estrategia en la que sólo usa la canción, en este caso recurre a diversas estrategias: juego libre con los objetos, canción dramatizada, lectura de láminas y juego del escondite.

\section{Los procesos cognitivos y discursivos, esenciales en los procesos de aprendizaje, se podrían desarrollar al trabajar con los niños estrategias como la explicación y la argumentación.}

La educadora aprovecha el juego libre para nominar los objetos y sus partes, haciendo énfasis a cada niño según el objeto, para lo cual hace uso del "lenguaje bebé, caracterizado por oraciones cortas pero gramaticales, muchas repeticione's, un ritmo de dicción lento, simplicidad sintáctica, tono alto y entonación exagerada y un mayor número de interrogativas y de imperativas de lo que sería normal" (Garton, 1994: 32). Según Garton este lenguaje es apropiado para la edad en la medida en que le permite al niño ubicarse en el aquí y el ahora, es decir en un tiempo y un espacio particular.

La educadora acompaña la acción con verbalizaciones que permiten el reconocimiento de texturas y formas acercando a los niños hacia formas descriptivas de los objetos, como a palabras que los clasifican y diferencian: "mira la ovejita, tiene lana... la vaca es suave, tiene cachos".

Retomando a Rogoff (1993: 99) se entiende como

todas las actividades de los cuidadores, junto con los esfuerzos del niño (intencionales o no) tienen como objeto captar información -a través de medios tales como la referencia social o las claves verbales y no verbales- sobre la naturaleza de las situaciones, el modo en que las interpretan los cuidadores y la forma más adecuada de enfrentarse a ellas.
En este sentido, es la educadora la que proporciona el marco de referencia y determina el tipo de experiencias y oportunidades que les ofrece a los niños.

Del uso de la canción se destaca la relación que estableció con el tema, articulándola a la actividad anterior, como también el acompañamiento constante de elementos paralingüísticos que ayudan a la construcción de significación en el niño.

Con la lectura de láminas la educadora recrea las características del animal y establece una contingencia a través de preguntas y respuestas que ella misma formula y responde, pero a través de las cuales promueve en los niños aprendizajes no sólo a nivel conceptual sino también discursivo.

A través del juego del escondite la educadora formula preguntas que motivan a los bebés a la búsqueda del objeto escondido, lo cual refleja procesos de interpretación del lenguaje del adulto por parte del niño, quien de igual forma responde simultáneamente con balbuceos, gestos y movimientos. Este proceso posibilita la construcción simbólica con un marcado carácter social y funcional.

En cuanto a la forma de interactuar, se pudo evidenciar que la educadora 1 propicia encuentros intencionales de interacción bidireccional en cada una de las rutinas del día (bienvenida, oración o desayuno) durante los cuales busca que los niños entren en contacto visual y corporal con ella, a lo que los niños responden de manera expresiva con su cuerpo, a través de la mirada, la sonrisa o el movimiento. En el momento de la bienvenida

[...] la educadora canta: "buenos días, amiguitos, ¿cómo están?” Y ella misma contesta, “Muy bien!” al tiempo que levanta los brazos. Los niños anticipan el saludo y suben los brazos antes que la educadora. Luego ella los saluda uno por uno, extendiéndole la mano y diciéndole su nombre, gesto ante el cual los niños responden dando la mano.

Se puede apreciar aquí como los niños responden a la acción de la educadora, incorporando pautas culturales de interacción social como el saludo. Las acciones de los niños están enton- 
ces apoyadas en las acciones y palabras de la educadora. Igualmente, en ello se aprecia un manejo temporal de las acciones del niño, quien es capaz, por un lado, de anticipar la acción de la educadora en el saludo, al saber qué sigue y, por otro, de esperar un turno de intervención (le dan la mano y lo saludan, él da la mano), lo cual se podría interpretar como un esbozo rudimentario de la estrategia discursiva del diálogo.

Es notoria la intención de la educadora de establecer un formato de alternancia en cada una de las escenas de interacción, durante las cuales ella les pregunta, hace pausas y responde, prestándoles su voz, como se aprecia en el siguiente registro: "E: Vamos a ponerle un nombre a la vaca. ¿Qué nombre le pondremos? ¡Susana!”

En este proceso de mutuo entendimiento, o de interacción bidireccional, se comparten significados de manera independiente de la comunicación lingüística. Para descubrir este proceso intersubjetivo es necesario observar sensiblemente las situaciones en las que los niños se anticipan a la comunicación de los adultos. Las acciones de los niños van más allá de mirar con atención el rostro de quien les habla: responden a las señales del adulto. Este tipo de respuestas o protodiálogos son identificadas desde muy temprana edad en los bebés, quienes con sus gorjeos, sonrisas, gestos y movimientos responden a las intervenciones del adulto.

Los niños obtienen pues información de las formas verbales y no verbales utilizadas por la educadora en el momento de la interacción. Sus gestos, sus movimientos, sus contactos, sus miradas, sus palabras, su tono, se convierten en referentes sociales o claves para la construcción de significado por parte de los niños. La comunicación no verbal es una parte inseparable del proceso global de comunicación y se usa para confirmar, apoyar, regular y a veces contradecir la comunicación verbal.

En relación con la educadora 2, en su planeación plantea un objetivo para el desarrollo de todas las actividades y los momentos pedagógicos, dejando ver claramente una intencionalidad con respecto al desarrollo del lenguaje: "A través de objetos significativos para los niños, crear espacios de interacción comunicativa para favorecer los diversos usos del lenguaje por medio de estrategias didácticas".
De igual forma, la planeación contempla la descripción y la narración como aspectos a desarrollar dentro de la dimensión comunicativa. Reconocer estas tipologías textuales de manera intencional en el trabajo con los niños permite apreciar un manejo significativo e interrelacionado de los elementos del discurso.

Así mismo, la educadora prepara la formulación de preguntas hacia los niños, las cuales son de carácter abierto e indagan por alguna información: “Quién es? ¿Cómo se llama? ¿Qué está haciendo? ¿De qué color es? ¿Por qué está triste o alegre?”

Estas preguntas, que no tienen la pretensión de evaluar lo que el niño sabe, propician la articulación de enunciados dentro de una dinámica discursiva, a la vez que lo familiarizan con la estrategia de la pregunta en sí misma.

Este tipo de formulaciones esbozado en las planeaciones refleja un mayor nivel de comprensión del lenguaje bajo un enfoque semántico y pragmático, y del aprendizaje desde una concepción constructiva y social, en la medida en que hace alusión a la interacción comunicativa, los usos del lenguaje y a objetos significativos para los niños.

Igualmente, se aprecia el valor que la educadora otorga a la planeación como un instrumento de orientación de la práctica, sin que ello implique, como lo manifiesta ella misma, perder flexibilidad al realizar la actividad en un contexto particular y de acuerdo a los intereses de los niños.

De otra parte se reconoce, tanto en la planeación como en el desarrollo de las actividades, una secuencia progresiva lineal, cuyo eje articulador, en este caso, está referido al tema de las etapas que viven los niños en su proceso de crecimiento, el cual está enmarcado dentro del proyecto de aula “Qué hacen papá y mamá?".

En la "bienvenida" planea y realiza, además del saludo, una canción alusiva a las etapas del crecimiento, Cuando yo era baby. En "vamos a explorar" realiza una visita a sala cuna para que los niños observen a los bebés: allí los niños saludan, acompañan la oración, observan la rutina de alimentación y juegan con los bebés. En "vamos a crear" la educadora saca de una bolsa fotos y objetos preferidos por los niños en su primera infancia para que sean identificados por ellos. De igual forma, los motiva 
a hacer descripciones y comentarios sobre éstos. En "vamos a jugar" plantea la exploración y juego libre con los objetos traídos por los niños. En el momento de "vamos a comer" contempla, además de la rutina de alimentación, la comparación entre las formas de comer de los bebés con las de los adultos.

En la secuencia descrita se destaca la relación entre los acontecimientos y el tiempo en el que son vividos, lo cual, aunque no es intencional, promueve la construcción de estructuras narrativas por parte del niño, favoreciendo la representación mental de los acontecimientos de vida, donde cada niño se asume como personaje principal. De esta manera, la secuencia permite al niño construir significaciones en torno a la realidad a través de la recreación de las imágenes y los recuerdos que tiene en su mente.

Así mismo, esta organización didáctica permitió a los niños establecer una relación significativa entre los diferentes momentos pedagógicos, mantener su interés y construir relaciones lógicas de orden temporal a través del lenguaje.

Cabe señalar el rol mediador de la educadora al utilizar la instrucción directa en situaciones referidas al aprendizaje de las convenciones sociales, tales como el saludo y la despedida.

De igual forma, se resalta el uso de la pregunta para promover procesos de identificación y descripción, los cuales fueron indicadores contemplados en la planeación. En su mayoría son preguntas cerradas, ya que muchas de ellas o ya indican la respuesta o sólo promueven la repetición de información sin llevar a establecer relaciones, analogías, explicaciones o argumentaciones, están centradas básicamente en confirmar una información, sin lograr lo formulado en la planeación, como se puede evidenciar el siguiente registro:

$\mathrm{E}:$ ¿De quién es este sonajero?

$\mathrm{N}$ : Mío.

E: ¡Ah! Es tuyo, Daniel. ¿Quién te lo regaló?

N: Mi mamá.

$\mathrm{E}:$ ¿De qué color es?

$\mathrm{N}$ : Verde.

$\mathrm{E}:$ ¿Qué otros colores tiene?

$\mathrm{N}$ : Azul y amarillo.

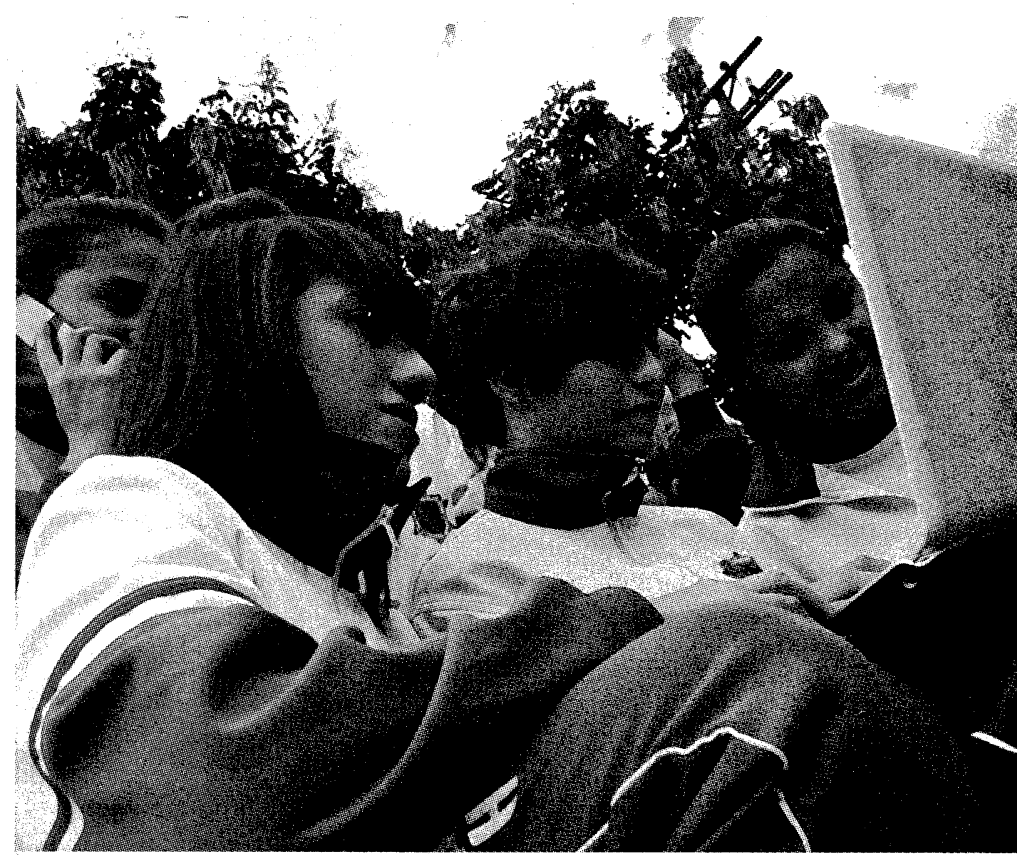

$\mathrm{E}:$ ¿De qué forma es?

$\mathrm{N}$ : Es una rueda.

E: Sí, es redondo.

Sin embargo, en comparación con la secuencia didáctica analizada en la primera estrategia, se puede reconocer una mayor riqueza en la interacción en la medida en que ésta se da no sólo educadora-grupo, sino fundamentalmente educadora-niño y promueve además una relación de cooperación en la que las preguntas generan niveles de contingencia, de tal forma que una respuesta del niño promueve nuevas preguntas de la maestra. Así se evidencia en el siguiente registro:

E: Miren. ¿Quién trajo este vestido tan lindo?

Nña: ¡Yo!

E: ¿Es tuyo, Daniela? ¿Este vestido te sirve todavía?

Nña: No.

E: ¿Por qué no lo usas?

Nña: Porque me queda chiquito.

$\mathrm{E}:$ ¿Cuándo lo usabas?

Nña: Cuando yo era bebé

$\mathrm{E}:$ ¿Y de qué color es?

Esta interacción podría haber sido más enriquecida si la educadora hubiera tenido en 
cuenta las preguntas pensadas en la planeación, ya que se centró en preguntas orientadas al qué y al cómo y muy pocas hacia el cuándo, el para qué y el por qué, lo cual limitó la expànsión de las respuestas por parte del niño, como también la oportunidad de argumentación y explicación. Es así como la narración, que era un propósito fundamental de la planeación, no se hizo evidente durante el desarrollo de la secuencia didáctica.

Se puede destacar finalmente que la docente brindó un espacio de juego libre con los juguetes, el cual favoreció la interacción entre pares en la que de manera espontánea los niños asumieron turnos y decisiones, pusieron en juego su fantasía y establecieron roles imaginarios que posibilitaron la creación de mundos posibles, la explicación de sus intenciones a otros y la comprensión del punto de vista de los demás.

\section{Construyendo autóniomamente}

Esta estrategia se encuentra en análisis actualmente y tiene como propósito que las educadoras estructuren y desarrollen una secuencia didáctica de forma autónoma, de manera que se evidencien los aprendizajes construidos durante todo el proceso de acompañamiento.

\section{Proyecciones}

Los desarrollos de esta investigación se constituirán en el punto de partida para una tercera investigación, cuyo propósito será construir sistemas de apoyo pedagógico para favorecer el desarrollo del lenguaje en los niños entre los 3 meses y los 5 años en términos del fortalecimiento de su competencia para la comprensión y producción de significados y sentidos a partir del uso de diferentes sistemas de signos, particularmente el sistema de la lengua. Ó

\section{Bibliografía}

Ander-Egg, E. (1991), El taller, una alternativa para la renovación pedagógica, Buenos Aires, Magisterio del Río de la Plata.
Baena, L. A. (1996), "Funciones del lenguaje y enseñanza de la lengua", en Lenguaje, núm. 24, Cali.

Braslavsky, B. (1997), La Escuela Puede. Una Perspectiva Didáctica, Buenos Aires, Aique.

Bruner, J. (1990), La elaboración del sentido, Barcelona, Paidós.

- (1995), El habla del niño, Barcelona, Paidós.

- (1997), La educación Puerta de la cultura, España, Visor.

- (2001), Desarrollo cognitivo y educación, $\mathrm{Ma}$ drid, Morata.

- (2001), Realidad mental y mundos posibles, Barcelona, Gedisa.

- (2001), Acción, pensamiento y lenguaje, Madrid, Alianza.

- (2002), Actos de significado, Madrid, Alianza.

Coll, S. (1990), Aprendizaje escolar y construcción del conocimiento, Buenos Aires, Paidós Educador.

Dubrovsky, S. (2000), Vigotsky. Su proyección en el pensamiento actual, Buenos Aires, Novedades Educativas.

Garton, A. (1994), Interacción y desarrollo del lenguaje y la cognición, Buenos Aires, Paidós.

- (1991), Aprendizaje y proceso de alfabetización, Buenos Aires, Paidós.

Halliday, M. K. (1994), El lenguaje como semiótica social, México, Fondo de Cultura Económica.

Hymes, D. (1972), Acerca de la competencia comunicativa, Bogotá, Mimeo.

Jaimes, G. y Rodríguez, M. E.(1996), Lenguaje y Mundos Posibles, Bogotá, Universidad Distrital-Colciencias.

- (1996), Lenguaje e Interacción en la Educación Preescolar, Bogotá, Universidad DistritalColciencias.

Jolibert, J. (1991), Formar niños productores de textos, Chile, Hachette.

- (1992), Formar niños lectores de textos, Chile, Hachette.

- (1999), "La Didáctica como campo propio, campo de acción y campo de investigación", en Transformar la formación docente, Chile, Santillana.

Lerner, D. (1993), Un desafio: Cambiar la propuesta didáctica vigente [documento mimeografiado], Buenos Aires. 
Litwin, E. (2000), Las configuraciones didácticas. Una nueva agenda para la enseñanza superior, Buenos Aires, Paidós.

Moll, L. C. (1990), Vygotsky y la educación, Buenos Aires, Aique.

Murcia Florián, J. (1992), Investigar para cambiar: Un enfoque sobre la investigación acción participante, Bogotá, Magisterio.

Pérez Serrano, G. (1994), Investigación cualitativa. Retos e interrogantes, Tomo I: Métodos, Madrid, La Muralla.

Porlan, R. y. Martin, J. (1997), El diario del profesor, España, Díada.

- (1997), Constructivismo y Escuela, España, Díada.

- (1995), "Qué y cómo enseñar desde una perspectiva constructivista", en Aportes, núm. 42, Bogotá, Dimensión Educativa.

Rincón, G. (2003), Entre textos. La comprensión de textos escritos en la educación primaria, Cali, Universidad del Valle-Colciencias.
Shon, D. (1983), La formación de profesionales reflexivos, Buenos Aires, Paidós.

Rogoff, B. (1993), Aprendices del pensamiento, Madrid, Paidós.

Tough, J. (1996), El lenguaje oral en la escuela, Madrid, Visor.

van Dijk, T. (1983), La ciencia del Texto,Barcelona, Paidós.

Vygotsky, L. S.(2000), El desarrollo de los procesos psicológicos superiores, Barcelona, Crítica.

- (1999), Pensamiento y lenguaje, Buenos Aires, Fausto.

Wertsch, J.(1995), Vygotsky y la formaciọn social de la mente, Barcelona, Paidós.

Zuluaga, O. L. (2003), Pedagogía y epistemología, Bogotá, Magisterio. 